\title{
Development of Permanent Mechanical Repair Sleeve for Plastic Pipe
}

\section{Semi-Annual Report}

\author{
Reporting Period: \\ October 1, 2004 - April 29, 2005 \\ Prepared by \\ Hitesh Patadia \\ Project Manager \\ April 29, 2005 \\ D.O.E. Contract No. 03-NT41880 \\ GTI Project No. 15446 \\ Gas Technology Institute \\ 1700 So. Mount Prospect Rd. \\ Des Plaines, IL 60018
}

\author{
For \\ Daniel Driscoll \\ Project Manager \\ U.S. Department of Energy \\ National Energy Technology Laboratory \\ 3610 Collins Ferry Rd. \\ P.O. Box 880 \\ Morgantown, W.V. 27507-0880
}




\section{DISCLAIMER}

This report was prepared as an account of work sponsored by an agency of the United States Government. Neither the United States Government nor any agency thereof, nor any of their employees, makes any warranty, express or implied, or assumes any legal liability or responsibility for the accuracy, completeness, or usefulness of any information, apparatus, product, or process disclosed, or represents that its use would not infringe privately owned rights. Reference herein to any specific commercial product, process, or service by trade name, trademark, manufacturer, or otherwise does not necessarily constitute or imply its endorsement, recommendation or favoring by the United States Government or any agency thereof. The views and opinions of authors expressed herein do not necessarily state or reflect those of the United States Government or any agency thereof. 


\begin{abstract}
The report presents a comprehensive summary of the prototype development process utilized towards the development of a permanent mechanical repair fitting intended to be installed on damaged PE mains under blowing gas conditions. Specifically, the step by step construction approach is presented and the experimental data to support the mitigation of ensuing slow crack growth (SCG) of the damage area.
\end{abstract}


Table of Contents

Page

Abstract.........................................................................

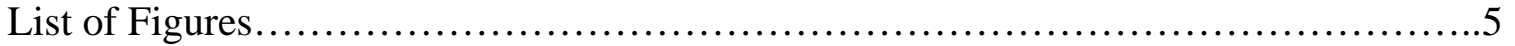

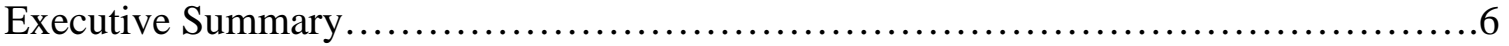

Experimental..................................................................... 7

Results and Discussion...........................................................

Conclusion.................................................................... 


\section{$\underline{\text { List of Figures }}$}

\section{Page}

Figure 1 Schematic Illustration of the Modified SCG Test Set-up.......... 7

Figure 2 Schematic Illustration of the $1^{\text {st }}$ Generation Mechanical Repair Fitting - Top View and Side View.......................... 8

Figure 3 Schematic Illustration of the $1^{\text {st }}$ Generation Mechanical Repair Fitting - Front View and Cut-out........................... 8

Figure $4 \quad$ Small clamping structure .................................... 10

Figure 5 Assembled small clamping structure ......................... 10

Figure $6 \quad$ Assembly .................................................... $\quad{ }_{11}$

Figure $7 \quad$ Assembly superstructure ..................................... 11

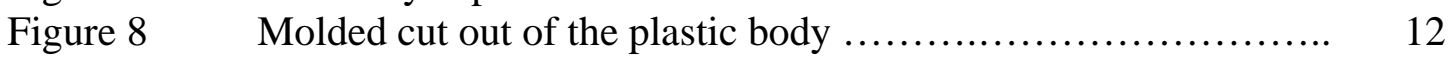

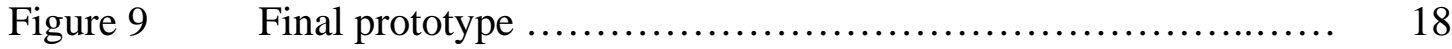




\section{Executive Summary}

The objective of this program is to develop a plastic pipe repair sleeve; a simple, mechanical device that can be installed on damaged 4" polyethylene (PE) pipe under system operating pressure. Once developed, subject the mechanical repair sleeve to comprehensive testing and evaluation in order to ensure that the newly developed fitting meets current standards and codes. At the onset of the program, with input and guidance from the project team, a product definition had been established:

- Design and development efforts should focus on 4-inch pipe size

- Fitting should conform to existing ASTM standards and specifications (ASTM D2513 and F1924 requirements, as applicable)

- Fitting should be able to be installed under blowing gas conditions at typical line pressures (60 psig)

- Fitting should have a target pressure rating of 100 psig (60 psig at a minimum)

- Once installed, the fitting design should effectively mitigate the continued propagation of the damage via the slow crack growth (SCG) failure mechanism

Based on the aforementioned product definition, GTI and its manufacturing partners undertook an iterative design process. A finite element model was created to ascertain the overall system stress between the pipe and installed fitting. The model was created in SolidWorks and the static analysis was perfomed with CosmosWorks utilizing a solid mesh and the FEEPLUS solver. A best-case design concept for the mechanical repair fitting was finalized. In essence, the mechanical repair fitting design consists of two half circular cylindrical parts that are hinged together. After they have encircled a pipe segment that has been damaged, these two parts can be mechanically fastened to each other to contain the damage. The repair fitting is not chemically bonded to the pipe. It is expected to stay in place by friction that is induced by tightening the bolts sufficiently that pressure is transmitted through compressed elastomeric rings at the ends of the sleeve. As these rings are the only portion of the sleeve that actually contact the pipe, there is an annular cavity between the inner wall of the fitting sleeve and the outer wall of the damaged portion of the pipe that is contained within the fitting body, as shown in Figure 1 below.
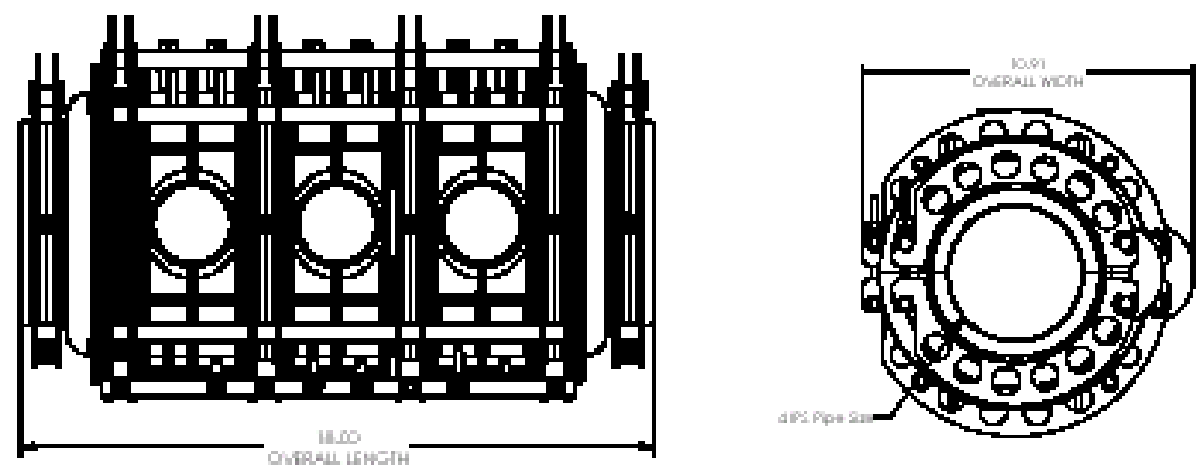

Figure 1: Illustration of the proposed design for Mechanical Repair Fitting 
Because the mechanical repair fitting is intended to cope with the entire range of damage that can occur in service, the principal design challenge was the repair of a "blowing" failure; i.e., a through wall opening in the pipe wall through which pressurized gas escapes. Thus, the unique feature of the mechanical repair fitting is three axially-aligned holes that will allow gas to escape during the repair procedure.

In addition to ensuring that the mechanical repair fitting can withstand internal pressures of up to $100 \mathrm{psig}$, another important consideration was its ability to effectively mitigate the propensity for continued Slow Crack Growth (SCG). To that end, a hybrid approach (analytical and experimental) was undertaken to ensure that the proposed fitting design effectively mitigates the SCG failure mechanism and the fitting to serve as a permanent repair option. Based on the results of the analytical model, it was demonstrated that the the annular cavity between the inner wall of the fitting sleeve and the outer wall of the damaged portion of the pipe that is contained within the fitting body would permit the equalization of pressures and thus eliminate the necessary driving force and amply mitigate any further continued SCG. The results of the analytical model were confirmed through experiments as presented in the sections to follow.

The next step in the overall program involved the prototype production of the "best case" design solution. This report presents a comprehensive summary of the prototype construction process and the experimental observations to mitigate the propensity for continued SCG failures of the damage area. 


\section{Experimental}

\section{Slow Crack Growth (SCG) Considerations}

In addition to ensuring leak tightness and the ability to be installed under blowing gas conditions, another important design consideration was the fittings ability to amply mitigate the propensity for slow crack growth in the axial direction beyond the end seals. Based on previous experience with steel band clamp fittings, it was hypothesized that an annular space was required in the fitting design that would equalize the pressure between the pipe and the annular space within the fitting. This would then remove the strain energy necessary to drive the crack. A comprehensive analytical model was presented in the previous semi-annual report.

In order to validate the analytical model, a modified experimental set-up was fabricated. Controlled sharp notches (95\% of the pipe wall thickness) were placed on three pipe specimens from both 2-inch medium density and high density PE materials. The 2-inch pipes were then inserted into 4-inch PE pipes and pressurized, as shown in Figure 1. The 2-inch pipes were allowed to fail on their own accord at room temperatures. The pipe specimen assemblies have been on test to date with only one failure. The failed pipe specimen was removed and the crack length was recorded. The assembly was then repressurized and monitored. The results of the testing showed that the modern PE materials have excellent SCG resistance characteristics and did not fail under pressure. The test specimens were removed and the damage lengths were measured. The results indicate that equalization of pressure does remove the necessary strain energy and effectively mitigates that propensity for the damage length to grow in the axial directions.

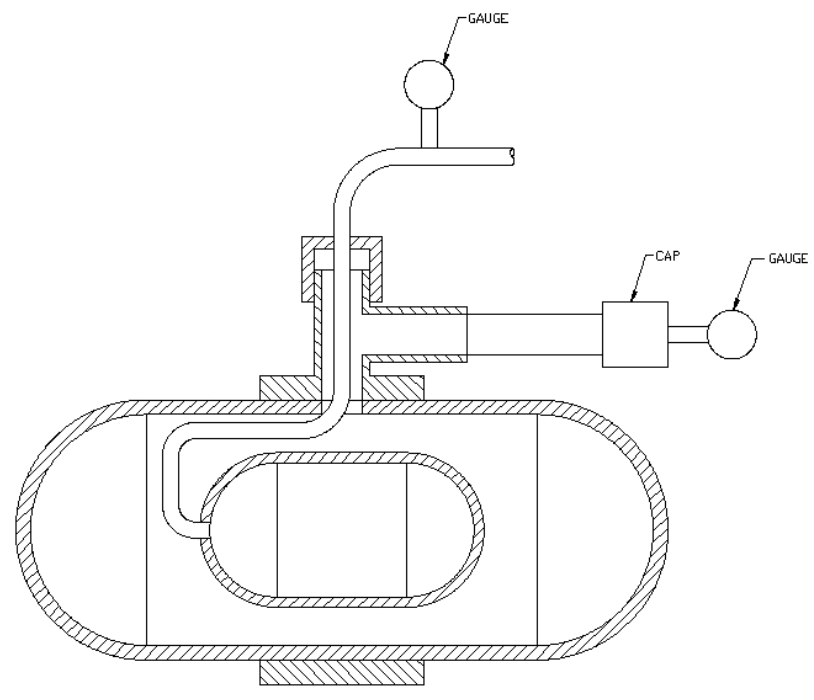

Figure 1: Schematic Illustration of the modified SCG test set-up 


\section{Prototype Development}

In the previous semi-annual report, it was noted that multiple design alternatives were investigated. Based on a series of Finite Element Analysis (FEA), it was observed that a small scale separation occurred after the fitting had been pressurized to 60 psig for a prolonged duration. To resolve this concern, the fitting design was modified with additional reinforcement members to ensure that the fitting was leak tight and was capable of withstanding the internal pressure over its intended design life. The final design concept, as shown in Figure 2 and 3, was accepted by the project team, and a decision was made to proceed to the prototype development.
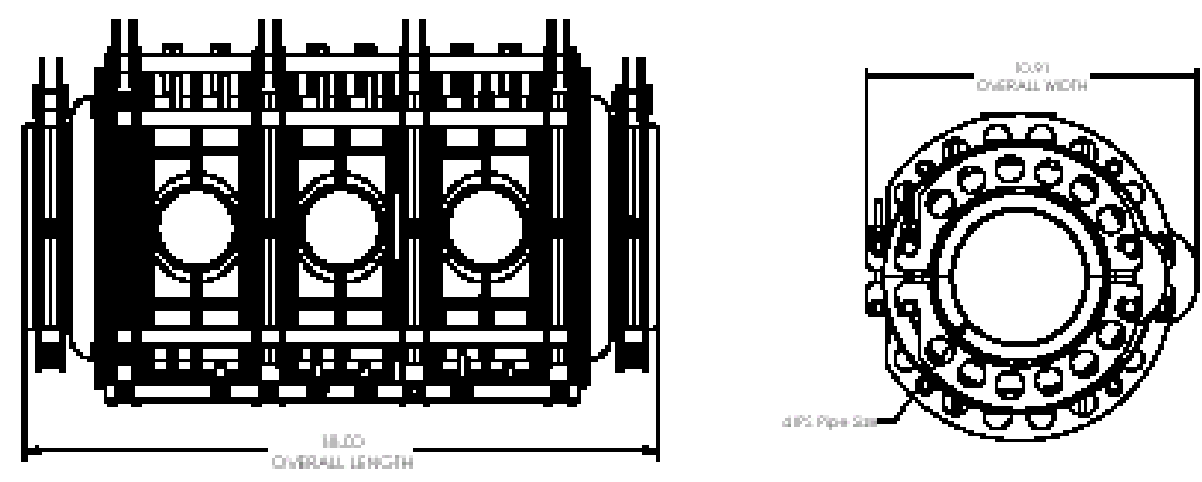

Figure 2: $\quad$ Schematic Illustration of the 2nd Generation Mechanical Repair Fitting Top View and Side View
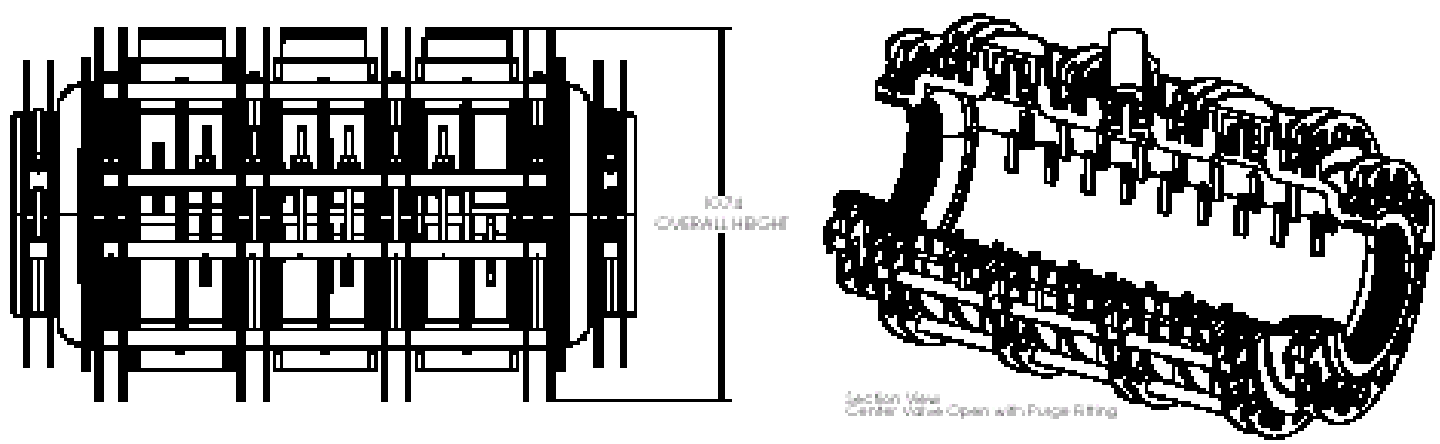

Figure 3: $\quad$ Schematic Illustration of the 2nd Generation Mechanical Repair Fitting Front View and Cut-out 
The seal system consisting of both the top half circumferential seals and the bottom half one piece circumferential and flange seal did not appreciably change. These seals were molded in a production grade compression mold out of the specified elastomer. There was a small scale improvements which were made to ensure an effective leak tight seal once installed. This included a change to a harder durometer material for the seals and a slightly smaller radius on the fitting circumferential sealing surface. The dimensional change was to compensate for the shrink rate of the seal material that lessoned the amount of interfacial contact pressure between the bottom and top seal.

The most significant design change was to the fitting clamping system structure. The goal of the prototype build of the clamping super structure was two-fold: first, to verify its functionality in properly holding the fitting together; second, developing a means to manufacture the fitting in an economical manner. As a result, short run tooling was made that would allow the manufacture of parts as close to the production process as possible. The additional height to the collar clamp channel made it impractical to form the channel as one piece. Additional welding fixtures would be necessary to fabricate the large collar clamp sub-assembly.

The entire clamp structure was made of 316 CRES (Stainless Steel). Each collar clamp half was made in two pieces by piercing and blanking the outline of the collar channel and then forming the perpendicular surface. For the prototype, the blanks were laser cut in their flat form to represent a part that would be produced on a pierce and blank die. Two simple tools, one (1) for the small collar clamp and one (1) for the large collar clamp, were built that could be loaded in a hydraulic press brake for forming the perpendicular radial surface. Two (2) blanks were loaded in the forming tool where one (1) cycle of the tool would produce a left and a right version of the part. Laser cutting the blank allowed for easily changing and optimizing the shape of the blank to produce a formed part needing only minimal cleanup before the welding process. The formed left and right parts were then placed into a welding fixture where a stitched seam weld was placed on the inside of the channel making the two pieces into one half $(1 / 2)$ of the collar clamp as shown in Figure 4.

Link plates for the clamp hinge were also laser cut for the prototypes where they will be pierced and blanked from a die in production. The threaded Swing Pin and Threaded Stud were welded together to form the tee bolt for the Small Collar Clamp. Two Small Collar Clamps halves were assembled together with the Link Plates, Link Pins and ERings. The tee bolt was crimped in to the saddle on one of the collar halves to capture the bolt and allow it to pivot. This with the Nylock nut completed the Small Collar Clamp assembly as shown in Figure 5. 


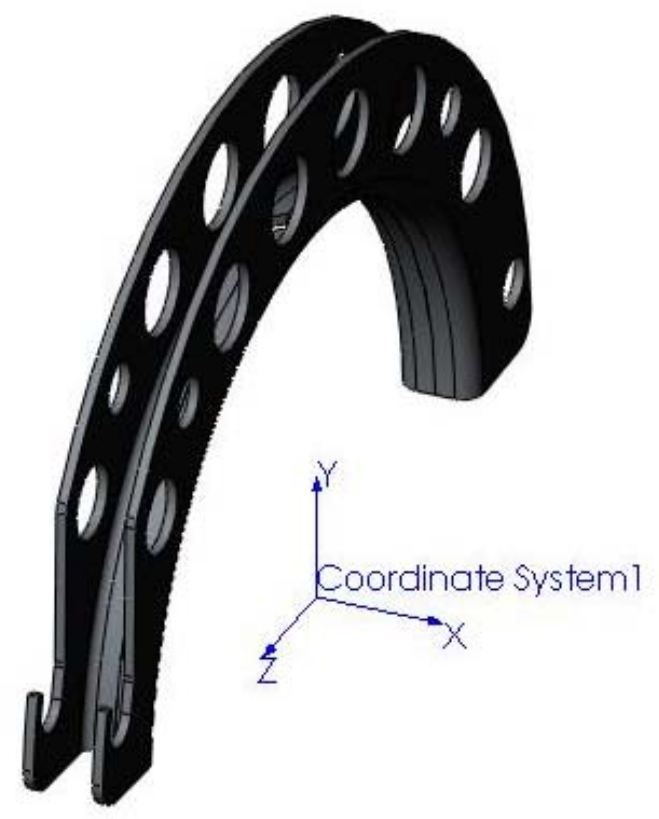

Figure 4: Small clamping structure

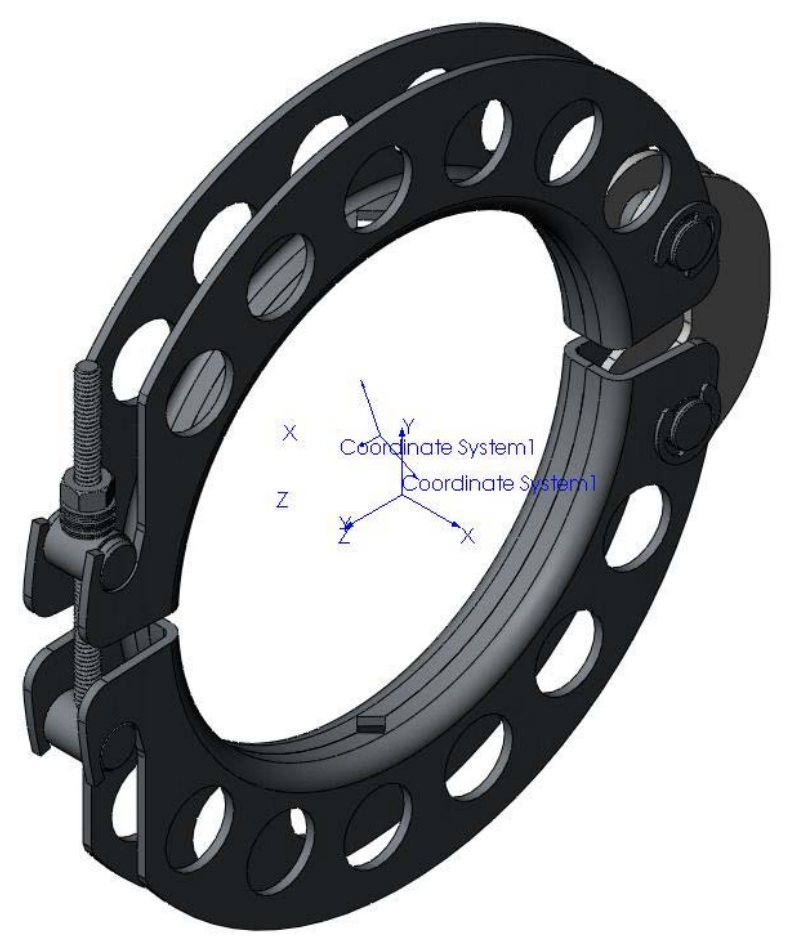

Figure 5: Assembled small clamping structure 
Four (4) Large Collar Clamp Halves were welded to two (2) Structural Clamp Rods in a welding fixture to form the Large Collar Clamp Sub-Assembly as shown in Figure 6.

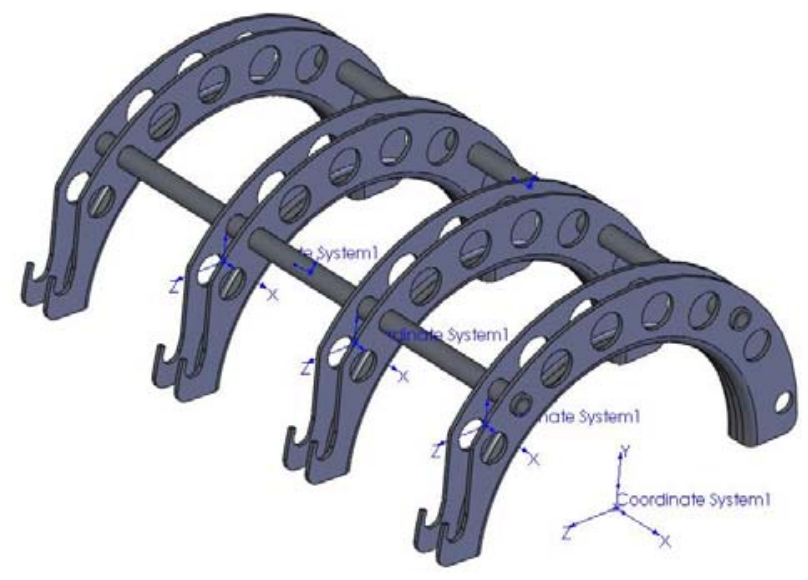

Figure 6: Assembly

Two Large Collar Clamp Sub-Assemblies were assembled together with the Link Plates, Structural Clamp Rods and Roto-Clips. The threaded Clamp Rod and Threaded Stud were welded together to form the ganged tee bolt for the Large Collar Clamp Assembly. The ganged tee bolt was crimped into the saddle on one of the Large Collar Clamp SubAssemblies to capture the bolt and allow it to pivot. This with the Nylock nuts completed the Large Collar Clamp Assembly as shown in Figure 7.

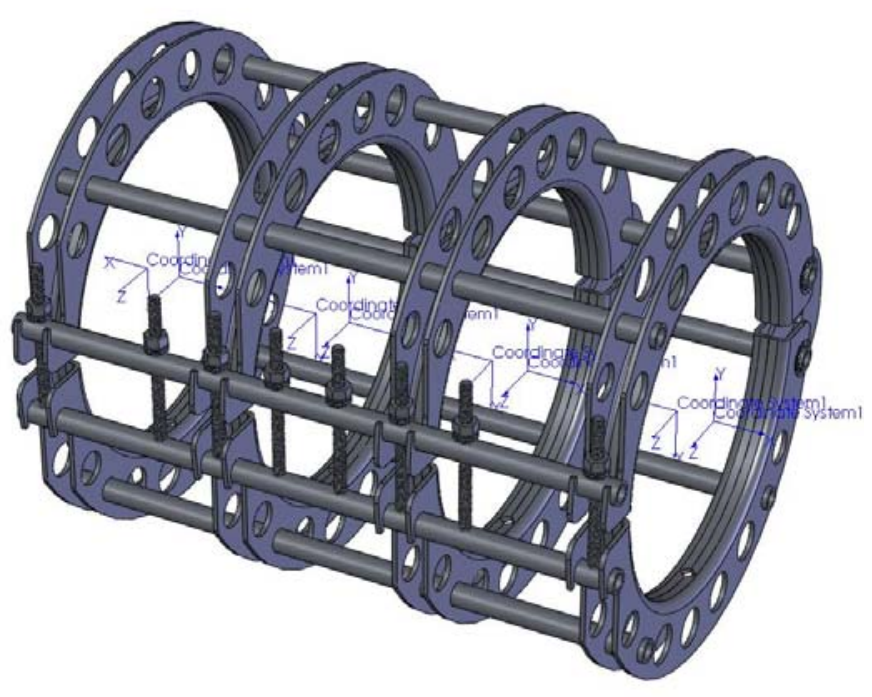

Figure 7: Assembly superstructure 
In addition to the clamping structure, the body of the prototype mechanical repair fitting was machined from solid blocks of plastic. The design material (PA 11) was not available in sufficient size to hog-out each half of the fitting. Polypropylene was available in blocks large enough to machine each half of the fitting so it was procured for the prototype fittings. As mentioned earlier the major changes to the fitting design were in the area of additional ribs and increased rib height. To expedite the prototype process the electronic model was transferred directly to the machine shop for tool path generation without the need for time-consuming detail drawing creation. Special care was taken in cutting the seal glands into the fitting halves so as closely as possible the as machined geometry would reflect that of the molded part. The Purge Valves and Purge Caps were also machined from Polypropylene. Figure 8 shows a cut-away view of the Generation III assembly with a purge fitting in the center port showing the valve in the open position.

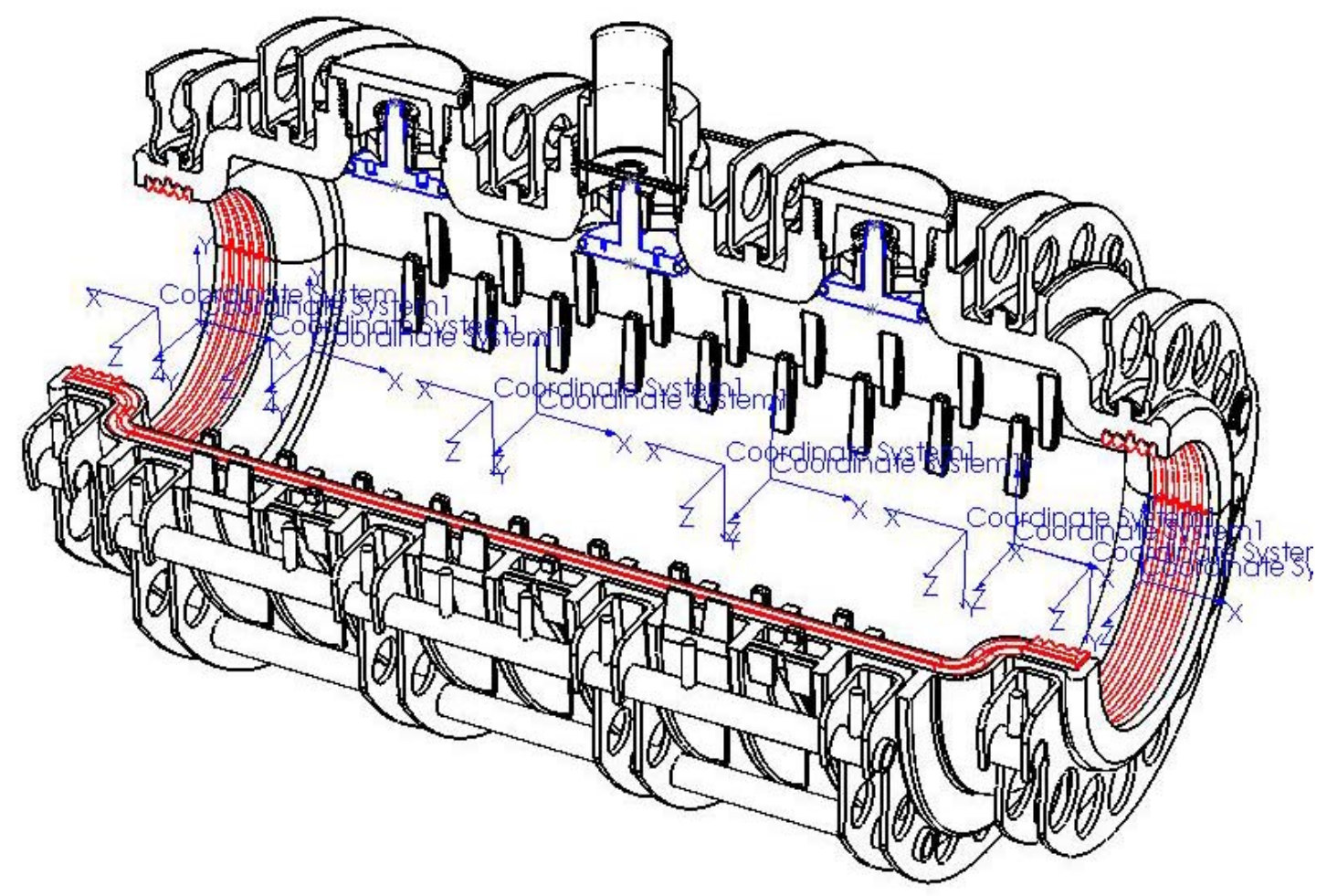

Figure 8: Molded Cut out of the plastic body 


\section{$\underline{\text { Results and Discussion }}$}

In essence, the mechanical repair fitting design consists of two half circular cylindrical parts that are hinged together. After they have encircled a pipe segment that has been damaged, these two parts can be mechanically fastened to each other to contain the damage. The repair fitting is not chemically bonded to the pipe. It is expected to stay in place by friction that is induced by tightening the bolts sufficiently that pressure is transmitted through compressed elastomeric rings at the ends of the sleeve. As these rings are the only portion of the sleeve that actually contact the pipe, there is an annular cavity between the inner wall of the fitting sleeve and the outer wall of the damaged portion of the pipe that is contained within the fitting body.

Because the mechanical repair fitting is intended to cope with the entire range of damage that can occur in service under typical line pressure of up to $60 \mathrm{psig}$, the principal design challenge is not only ensuring the repair of a "blowing" failure; i.e., a through wall opening in the pipe wall through which pressurized gas escapes, but also ensuring a leak tight seal and ability to withstand the internal pressures. To that end, based on a series of FEA analysis and the prototype build, as shown in Figure 9, it has been shown that the objectives of this program can be successfully achieved.

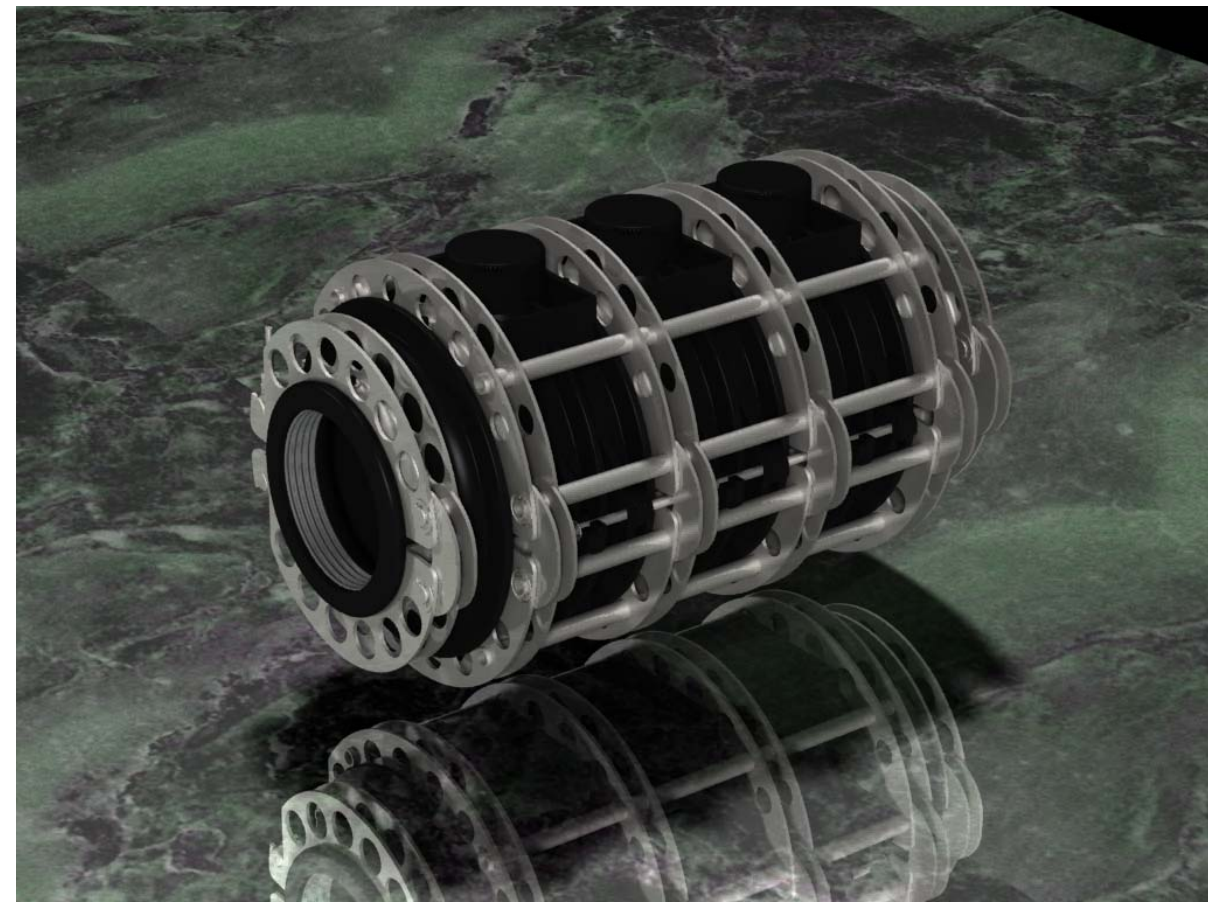

Figure 9: Final prototype 


\section{Conclusion}

GTI, under the sponsorship of the DOE-NETL Contract: 03-NT41880.000 and utility sponsors, has been engaged in a program to design and develop a plastic pipe repair sleeve; a simple, mechanical device that can be installed on damaged (scratched / gouged) 4" polyethylene (PE) pipe under system operating pressure. An initial design concept has been developed. A program to perform comprehensive testing and evaluation in order to ensure conformity to current standards and codes has been outlined for the proposed design.

Having successfully completed both the conceptual design and the prototype build, GTI has initiated the production of multiple parts made from production tooling for subsequent industry and ASTM related testing. 


\section{$\underline{\text { List of Acronyms and Abbreviations }}$}

PE

ASTM

SCG

LEFM

MRS

OD

ID

PA 11

GTI

$\mathrm{K}$

a

c

h

$\sigma$

$\phi$

$\mathrm{K}_{\mathrm{D}}$

$t_{i}$

B

A

$\mathrm{m}$
Polyethylene

American Society for Testing and Materials

Slow Crack Growth

Linear Elastic Fracture Mechanics

Mechanical Repair Sleeve

Outer Diameter

Inner Diameter

Polyamide 11

Gas Technology Institute

Stress intensity factor

crack depth

one-half of the surface length of the crack

wall thickness

remote tensile stress

angle of penetration

Stress intensity factor

time required for SCG to be initiated

material constant

material constant

material constant 